\title{
CRITÉRIOS OBJETIVOS PARA APLICAÇÃO DO PRINCÍPIO DA VEDAÇÃO DOS EFEITOS CONFISCATÓRIOS DO TRIBUTO
}

\author{
Leiner Marchetti PEREIRA ${ }^{1}$
}

Giovanni Jonatas de SOUZA ${ }^{2}$

\begin{abstract}
${ }^{1}$ Advogado, Professor Universitário, Coordenador de Curso. Especialista em Administração Pública. Mestre em Direito pela Universidade Vale do Rio Verde - UninCor. leinermarchetti@ hotmail.com

${ }^{2}$ Bacharelando em Direito pela Universidade Vale do Rio Verde - UninCor. giovannisouza92@live.com
\end{abstract}

Recebido em: 08/09/2016 - Aprovado em: 22/03/2017 - Disponibilizado em: 01/07/2017

\begin{abstract}
RESUMO:
Analisar-se-á por intermédio da presente pesquisa o princípio constitucional tributário da vedação dos efeitos confiscatórios em razão da lacuna existente na legislação pátria quanto aos critérios objetivos de sua efetiva aplicação em defesa dos contribuintes frente ao poder de tributar estatal. Para tanto, tratar-se-á do poder de tributar dos entes federados, suas mutações ao decorrer do tempo, bem como suas respectivas limitações, considerando ser a tributação a principal fonte de receita para que o Estado cumpra seus objetivos constitucionalmente definidos. Evidenciar-se-á as limitações constitucionais ao poder de tributar, suas limitações, com especial ênfase ao princípio da vedação dos efeitos confiscatórios, o qual possui natureza constitucional, com previsão no art. 150, inciso IV, da Constituição da República Federativa do Brasil de 1988, visando esclarecer quais são os critérios objetivos da aplicação do referido princípio que devem ser respeitados pelo fisco na atividade de instituição e aplicação da lei tributária, lastreado na jurisprudência pátria e na doutrina específica.

Palavras-chave: Direito Tributário. Poder de Tributar. Limitações. Vedação dos Efeitos Confiscatórios. Critérios objetivos.
\end{abstract}

\begin{abstract}
We will analyze through the present research the constitutional principle of taxation of the prohibition of confiscatory effects due to the existing gap in the national legislation regarding the objective criteria of its effective application in defense of taxpayers in face of the power to tax state. In order to do so, it will be the power to tax the federated entities, their mutations over time, as well as their respective limitations, considering that taxation is the main source of income for the State to fulfill its constitutionally defined objectives. The constitutional limitations of the power to tax, its limitations, with special emphasis on the principle of the prohibition of confiscatory effects, shall be evidenced, which has a constitutional nature, provided for in art. 150, item IV, of the Constitution of the Federative Republic of Brazil of 1988 , in order to clarify what are the objective criteria of application of this principle that must be respected by the tax authorities in the activity of institution and application of tax law, backed by jurisprudence and doctrine specific.
\end{abstract}

Keywords: Tax Law. Power of Tax. Limitations. Fencing of Confiscatory Effects. Objective criteria.

\section{Introdução}

A presente pesquisa tem por escopo determinar critérios objetivos para aplicação do princípio de vedação dos efeitos confiscatórios do tributo, para tal consecução utilizar-se-á o método analítico, bem como a metodologia empregada será de pesquisa bibliográfica.

A legislação pátria é vaga ao definir critérios para utilização do referido princípio, previsto na Constituição Federal de 1988, em seu artigo 150, inciso IV, não o bastante sua 
lacuna legal, as particularidades de cada caso o torna ainda mais complexo. Logo, exige-se uma pesquisa junto a doutrinadores, jurisprudências e textos científicos para que em um emaranhado de informações, possa-se delimitar padrões concretos e objetivos na determinação dos efeitos confiscatórios dos tributos.

Inicialmente tratar-se-á do poder de tributar do Estado, suas mutações ao decorrer dos tempos, as atuais características intervencionistas como principal fonte de riqueza do Estado e a relação com o particular advinda do tributo. Demonstrará, neste viés, o surgimento do Estado Social com uma atividade tributária cada vez mais ativa, sendo, pois, a tributação é a principal receita para que o Estado cumpra seus objetivos, a qual se difere do conceito de tributo.

Em seguida, cuidar-se-á da limitação do poder de tributar, vislumbrando a função do estado em prover as necessidades da sociedade, adquirindo assim, poder de estipular da população participação nos encargos públicos, por meio dos tributos, afinal as receitas estatais provêm do particular. Por conseguinte, o Estado possui poder de tributar, todavia referido poder foi limitado pelo constituinte; limitação que se expressa sob duas formas, seja por princípios ou por imunidades. Discorrerá de forma sucinta sobres os princípios da legalidade, anterioridade tributária, isonomia tributária, irretroatividade tributária, uniformidade geográfica, não limitação ao tráfego de pessoas e bens e a reserva do pedágio, nãocumulatividade de tributos, seletividade, não discriminação baseada em procedência ou destino.

No mesmo padrão, discorrer-se-á sobre as imunidades, normas constitucionais que afastam a incidência tributária sobre certas pessoas ou itens; o texto constitucional prevê imunidade sobre as entidades políticas, templos religiosos, a imprensa, obras musicais e ainda as imunidades não autoaplicáveis.

Por fim, abordar-se-á especificadamente o princípio da vedação dos efeitos confiscatórios, o qual possui natureza constitucional, com previsão no artigo 150, inciso IV, da Constituição Federal de 1988, o qual se apresenta como a absorção total ou parcial da propriedade do contribuinte por meio do tributo. Todavia, a delimitação de quando se encontra diante dos efeitos confiscatórios não possuiexpressa previsão legal, contudo a jurisprudência e doutrina apontará a possibilidade, de se analisar os tributos individualmente ou em sua totalidade, da definição dos efeitos confiscatórios caso a caso, como pode ocorrer, com as taxas, contribuições, incidências tributárias sobre produtos e serviços, além de momentos em que certos tributos passam a ter efeitos de confisco, como na progressividade, quando passam a invadir o patrimônio, seja ultrapassando os limites do mínimo existencial, ou então, na proporção de parcela 
que caberá ao Estado em face à parcela que restará ao contribuinte seja evidentemente desproporcional.

Desta forma, a pesquisa busca conceder objetividade na utilização do princípio constitucional do não confisco tributário, visando proporcionar maiores garantias aos contribuintes diante de uma carga tributária que assola a classe produtiva em nosso país.

\section{Do Poder de Tributar}

Desde os tempos imemoriais verificase a existência de tributos, inicialmente pagos voluntariamente pelos cidadãos em um Estado Patrimonial, objetivando sua importância para melhoria do bem comum da polis.Para LuísEduardo Schoueri“"este modelo de Estado Patrimonial é aquele no qual o Estado, valendo-se de seus próprios meios, obtém o de que necessita para sua subsistência. Ou seja: o Estado, enquanto agente econômico,gera a riqueza que consome"(Schoueri, 2014 , p.26).Excepcionalmente, em casos de guerras surgiam tributos obrigatórios.

O poder de tributar sofreu mutações ao decorrer dos tempos, ganhando características intervencionistas, como no Estado de Polícia e o Estado Fiscal ou simplesmente Estado do Imposto. Neste último, não gerador mais de sua própria riqueza, mas esta advinda do particular, o qual transfere parte do que possui ao Estado, assumindo feições minimalistas, ou seja, não intervencionista,onde dependia da aprovação do parlamento para intervir na economia, evitando atos arbitrários.

Advindoo Estado Social Fiscal onde agressivamente cresce sua necessidade de recursos, como um expressivo aumento da carga-tributária para sustentar os programas sociais implementados por ele. O qual, para Sabbag (2014, p. 39):

Necessita, em sua
atividade financeira, captar
recursos materiais para
manter sua estrutura,
disponibilizando ao
cidadão-contribuinte os
serviços que lhe compete,
como autêntico provedor
das necessidades coletivas.

Logo, o Estado, soberano como é, possui poder para tributar, assim obrigando, por meio da tributação, que o cidadão cumpra sua parte na relação jurídica poder $\mathrm{x}$ direito $\mathrm{e}$ não poder $\mathrm{x}$ força, pois poder de tributar é:

Um poder de direito,
lastreado no consentimento
dos cidadãos, destinatários
da invasão patrimonial,
tendente à percepção do
tributo. Se há em seu
emprego uma parcela de
força, ela se mostra
institucionalizada, dotada
de juridicidade (Sabbag,
2014, p. 58).

Nesta relação jurídica, vislumbramos dois polos, o Estado chamado de fisco ${ }^{1}$, polo ativo eo cidadãono polo passivo denominado de contribuinte.

\footnotetext{
1،'O termo 'fisco' no Império Romano, era um cesto de junco, utilizado pelos soldados romanospara arrecadação de tributos" (Sabbag, 2014, p. 41)
} 
Tendo por meio da tributação,principal receita para cumprir seus objetivos elencados no art. $3^{\circ}$ da Constituição da República Federal do Brasil de $1988^{2}$, fazendo-se necessário a positivação de normas, o Direito Tributário, coibindo atos arbitrários do Estado. Paulo de Barros de Carvalho (CARVALHO,2004, apud Sabbag, 2014, p. 40)leciona que:

Direito tributário é o ramo
didaticamente autônomo
do Direito, integrado pelo
conjunto de proposições
jurídico-normativas, que
correspondam, direta ou
indiretamente, à
instituição, arrecadação e
fiscalização de tributos,
conclui Sabbag que o
Direito Tributário é o
conjunto de normas que
regula o comportamento
das pessoas de levar
dinheiro aos cofres
públicos

Insta salientar que Poder de Tributar difere de tributo, no próprio Código Tributário Nacional o legislador expressa que:

\begin{abstract}
Art. $3^{\circ}$ Tributo é toda prestação pecuniária compulsória, em moeda ou cujo valor nela se possa exprimir, que não constitua sanção de ato ilícito, instituída em lei e cobrada mediante atividade administrativa plenamente vinculada.
\end{abstract}

2 Art. $3^{\circ}$ Constituem objetivos fundamentais da República Federativa do Brasil:

I - Construir uma sociedade livre, justa e solidária;

II -Garantir o desenvolvimento nacional;

III - Erradicar a pobreza e a marginalização e reduzir as desigualdades sociais e regionais;

IV - Promover o bem de todos, sem preconceitos de origem, raça, sexo, cor, idade e quais outras formas de discriminação.
Hugo de Brito Machado nos resume em dizer que

(...) enquanto o Tributo
visa suprir os cofres
públicos de recursos
bastantes ao custeio das
atividades estatais, no
plano da arrecadação, o
Direito Tributário almeja
efetivar o controle do
poder de tributar,
perpetrado pelo Estado que
tributa (MACHADO,
2008, p.50).

Diante de tais necessidades, o Poder Constituinte tipificou na Magna Carta os pilares do Direito Tributário sub duas formas: a primeira relacionada a distribuição das competências, previstas nos artigos 153, 155 e 156 da Constituição da Republica de 1988, de forma que o poder não esteja centralizado em um único órgão; a outra relacionando os princípios jurídicos norteadores do Direito Tributário, previstos nos artigos 150, 151 e 152 do Texto Constitucional, impedindo atos arbitrários do Estado.

\section{Da limitação do Poder de Tributar}

De início, vale ressaltar que, "tendo o Estado surgido com a função precípua de prover necessidades coletivas, há de estar ele munido do poder de exigir dos governados uma participação nos encargos públicos" (Sabbag, 2014, p.53), ou seja, o Estado possui o Poder de Tributar, todavia não é ilimitado, pois o legislador constituinte originário o limitou no texto constitucional, visando proteger os eventuais contribuintes contra o 
poder estatal de invasão patrimonial. Carrazza (2008, p.489) afirma que a força tributante Estatal não atua livremente, sendo esta limitada pelo direito positivo, previsto na Carta Magna nos artigos 150 a 152 de forma direta, dentre outras previsões que afetam indiretamente na seara tributária; as quais, manifestam sob a forma de princípios e imunidades.

As limitações ao poder de tributar, ressaltando sua interferência ao direito de propriedade do indivíduo, além de caracterizar uma garantia individual é tida para grandes estudiosos como cláusula pétrea $^{3}$; Ricardo Alexandre (2015, p.109) simplifica o tema ao dizer que tal entendimento não alcança todas as limitações, mas $\operatorname{sim}$ as que se enquadram como: "garantias individuais do contribuinte" e as "que constituem proteção às outras cláusulas pétreas". Assim também afirmado por Mazza ao expor que “os princípios são garantias fundamentais do contribuinte e, ao mesmo tempo, limitações constitucionais ao poder de tributar" (MAZZA, 2015, p.250),sendo assim, cláusula pétrea, pois conforme previsto no texto constitucional em seu artigo $60, \S 4^{\circ}, \mathrm{IV}$ :

\footnotetext{
Art. 60. (...)

$\S 4^{\circ}$ Não será objeto de deliberação a proposta de emenda tendente a abolir: (...)

IV - direitos e garantias fundamentais.
}

\footnotetext{
3 Alguns doutrinadores mais modernos preferem a utilização da terminologia "proibição do retrocesso".
}

Neste diapasão, Ricardo Alexandre (2015) relata que o Supremo Tribunal Federal entendeu ser inconstitucional a exclusão do princípio da anterioridade quando da promulgação da EC 3/1993, exatamente por ferir uma garantia individual do contribuinte.

No mesmo sentido, Alexandre Mazza conclui que o "Texto de 1988 confere aos princípios natureza dúplice, do ponto de vista do fisco, limitações do poder de tributar, e representando, para o contribuinte, garantias fundamentais" (MAZZA, 2015, p.250), afirmando que princípios são preceitos instituídos em favor do contribuinte e que contrarias aos interesses do Fisco, nunca o contrário, pois são proteções sistêmicas erigidas para defesa da parte hipossuficiente na relação Fisco-contribuinte. Logo, referido autor conclui que princípios tributários são preceitos fundamentais de observância obrigatória pelo legislador e pelo Fisco, cujo descumprimento causa a nulidade do tributo, especialmente a sua cobrança.

Ainda sobre seu conceito, Schoueri (2014) nos ensina que princípio, deriva-se da palavra "base", de tal modo, que surge um ramo científico autônomo quando se identifica princípios comuns, onde possui mais vigor e serve de vetores ao Direito Tributário. Sendo sua importância conhecida pelo legislador, inclusive o constituinte, os quais, devem ser observados tanto pelo legislador como o aplicador da norma tributária. Outrora, alguns princípios não se encontram expressos nos textos, pois decorrem de uma leitura atenta dos textos legais. Celso Antônio Bandeira de Melo (Melo, apud, Alexandre, 2015, p. 111 e 112)relata que 
Princípio é, por definição, mandamento nuclear de um sistema, verdadeiro alicerce dele, disposição fundamental que se irradia sobre diferentes normas, compondo-lhes o espírito e servindo de critério para a sua exata compreensão e inteligência exatamente por definir a lógica e a racionalidade do sistema normativo, no que lhe confere a tônica e lhe dá sentido harmônico.

De tal maneira, pode-se observar os princípios expressos e tipificados no texto constitucional, sendo:

\section{a) Princípio da Legalidade Tributária:} insculpido no art. 150, I, da Constituição Federal e no art. 97 do Código Tributário Nacional, funda-se na ideia que nenhum tributo será instituído, nem aumentado, a não ser através de lei, sob pena de inconstitucionalidade. Referido princípio comporta exceções, sendo hipóteses que sofrem mitigação, descritas pela própria Constituição como os previstos no art. 153, $\S 1^{\circ}$ da Constituição Federal, por possuírem função extrafiscal;

\section{b) Princípio da Anterioridade Tributária:} com previsão no art. 150 , III, $b$ e $c$, da Constituição, tal princípio impede a voracidade fiscal de criar ou majorar tributos no mesmo exercício financeiro; objetiva-se que o contribuinte tenha segurança jurídica no sentido de evitar ser surpreendido no mesmo exercício fiscal por novos ou majorados tributos, não se confundindo com a anualidade $^{4}$ prevista na Constituição de 1967; tal ideia é reforçada pelo princípio da anterioridade nonagesimal o qual exige-se que a norma tributária deve respeitar o período mínimo, vacatio legis, de noventa dias da data de sua publicação até a data em que passaria a ser realmente aplicado. Além das exceções previstas no art. $153, \S 1^{\circ}$ da Constituição, vale ressaltar que normas sobre Imposto de Renda (IR), alterações nas bases de cálculos do IPVA e IPTU não estão sujeitas a anterioridade nonagesimal, já as normas que alteram o IPI e as contribuições especiais sociais para a seguridade social só estão vinculadas a este princípio, excepcionando referido princípio em sua variação nonagesimal;

\section{c) Princípio da Isonomia Tributária:} previsto no art. 150, II, da Carta Magna, tratase de corolário do Princípio da Isonomia, expresso no artigo $5^{\circ}$ da Constituição Federal, proibindo que a entidade tributante institua ou cobre tributos de forma desigual entre contribuintes que se encontrem nas mesmas condições jurídicas; ou seja, devem oferecer tratamento uniforme a todos que se encontrem em condições iguais. Derivando-se dele o princípio da capacidade contributiva, devendo os tributos atingirem seus contribuintes de forma pessoal, conforme sua capacidade tributária, sem infringir a isonomia;

\footnotetext{
${ }^{4}$ Para que houvesse a cobrança de um novo tributo, no mesmo exercício financeiro, este deveria ter previsão na respectiva lei orçamentária, tal princípio não foi recepcionado pela Constituição de 1988.
} 


\section{d) Princípio da Irretroatividade}

Tributária: com tipificação no art. 150, III, $a$, da Constituição, tal princípio estabelece que não haverá cobrança de tributo sobre fatos que aconteceram antes da entrada em vigor da lei que o instituiu ${ }^{5}$, ou seja, veda que leis novas alcancem fato pretérito. O CTN prevê duas hipóteses, que apesar de aparentarem exceções, são benéficas ao contribuinte, os casos de normas interpretativas e lei benigna, todavia são exceções a tal princípio;

\section{e) Princípio da Uniformidade Geográfica:} tipificado pelo art. 151, I, da Constituição, visa a integralidade nacional, onde os entes com capacidade tributária não podem instituir tributos diferentes em seu território competente, no caso, por exemplo, é vedado a União impor obrigação que implique distinção ou preferência em detrimento de um Estado, Distrito Federal ou Município. Todavia será aceito a União criar incentivos fiscais com a finalidade de promover $\mathrm{o}$ desenvolvimento de determinada região;

\section{f) Princípio da Não Limitação ao Tráfego} de Pessoas e Bens e a Reserva do Pedágio: previsto no art. $150, \mathrm{~V}$, da Carta Magna, tal garantia proíbe a criação de tributos que impeçam ou limitem a intermunicipalidade e

\footnotetext{
${ }^{5}$ Princípio da irretroatividade (Direito Tributário) Direito $e$ Leis. Disponível em: $<$ http://www.direitoeleis.com.br/index.php?title=Princí pio da irretroatividade (Direito Tributário)\&oldid=4960>. Acesso em: 23 de novembro de 2015.
}

interestadualidade, garantindo o direito de ir e vir, corroborando para a liberdade de locomoção no território nacional. Vale ressaltar que tal imposição não impede a tributação sobre a circulação em operações interestaduais ou intermunicipais, ademais, insta salientar que a Carta Magna excepciona a cobrança de pedágios. Logo, comportam duas atenuantes, a cobrança de pedágios e a cobrança de ICMS pelas autoridades fiscais nos postos de fiscalização;

\section{g) Princípio da Não-Cumulatividade de}

Tributos: com noção nos artigos $153, \S 3^{\circ}$, II, e $155, \S 2^{\circ}$, I, da Constituição: visa proibir que determinados tributo sejam cobrados em cascatas, portanto, visa obstar que recaia sobre ele mesmo, quando em sua base de cálculo está inserido sua incidência na operação anterior. Melhor dizendo, é vedado que seja cobrado tributo de tributo. Todavia tal princípio surge efeito somente aos impostos plurifásicos, como ICMS, IPI e outros;

h) Princípio da Seletividade: com relato nos artigos $153, \S 3^{\circ}$, I, e $155, \S 2^{\circ}$, III, da Constituição, Mazza (2015) explica que tal princípio exige que as alíquotas de ICMS e IPI sejam graduadas de acordo com a essencialidade do produto, ou seja, quanto maior a importância social da mercadoria tributável menores serão suas alíquotas;

\section{i) Princípio da Não Discriminação Baseada em Procedência ou Destino: previsto no art.}


152 da Constituição, visa proibir o estabelecimento de diferenças tributárias, "favores fiscais", sobre bens e serviços de qualquer natureza em decorrência de sua procedência ou destino, buscando minorar a prática de guerra tributária. Ressalvado o direito de a União estabelecer benefícios fiscais, para equilíbrio econômico de certas regiões, bem como outros benefícios expressos na Constituição.

Por outro lado, além dos princípios, as limitações ao poder de tributar também se dão por meio das imunidades, estando sua maioria prevista no artigo 150 da Constituição Federal; as imunidades "são normas constitucionais que limitam a competência tributária afastando a incidência de tributos sobre determinados itens ou pessoas" (MAZZA, 2015, p.349), as quais, "visam preservar valores políticos, religiosos, sociais e éticos, colocando a salvo da tributação certas situações e pessoas (físicas e jurídicas)"(SABBAG, 2016, p.295). Referido autor afirma ainda, que:

O legislador ordinário, quando descreve a norma jurídica, está impedido de inserir no polo passivo da relação jurídico-tributária as pessoas e as situações guarnecidas pelo manto protetor de uma norma imunizante, sob pena de inafastável

inconstitucionalidade

(SABBAG,2014, p.297)
Impedindo que ente tributante inaugure a relação jurídica.

Já Hugo de Brito Machado conceitua imunidades como "o obstáculo criado por uma norma da Constituição que impede a incidência de lei de tributação sobre determinado fato, ou em detrimento de determinada pessoa, ou categoria de pessoas" (MACHADO, 2008, p.230). Todavia, vale ressaltar que imunidade e isenção não se confundem ${ }^{6}$.

São tipos de imunidades previstas no texto Constitucional:

\section{a) Imunidades das Entidades Políticas:} insculpida no art. 150, inciso VI, “a” e $\$ 2^{\circ}$, significa que o pacto federativo prevê uma convivência harmônica das entidades políticas, proibindo a incidência de imposto mutuamente pelos entes federados. Fundamenta-se na supremacia do interesse público sobre o privado e a ausência da capacidade contributiva das pessoas políticas; afastando a mutua cobrança de impostos entre

\footnotetext{
${ }^{6}$ As imunidades possuem bases na Constituição e as isenções uma possibilidade normativa (legislação ordinária). Luciano Amaro preconiza que "a diferença entre a imunidade e a isenção está em, a primeira atua no plano de definição de competência, e a segunda opera no exercício da competência. " (AMARO,2008, p.152). Assim, melhor explicado por Sabbag ao dizer que "para o STF o que se inibe na isenção é o lançamento do tributo, tendoocorrido fato gerador e nascido o liame jurídico-obrigacional. $\mathrm{Na}$ imunidade, não há que se falar em relação jurídico-tributária, uma vez que a norma imunizadora está fora do campo de incidência do tributo, representando o obstáculo, decorrente de regra da Constituição, à incidência de tributos sobre determinados fatos, situações ou pessoas. " (SABBAG, 2016, p.299)
} 
eles, não alcançando a cobrança mútua de taxas. Vale ressaltar, que tal entendimento, estende-se em certos casos às autarquias e fundações públicas;

b) Imunidades dos Templos Religiosos: previsto no art.150, inciso VI, alínea "b" e $\S 4^{\circ}$, reafirma a neutralidade do Estado laico com a busca da liberdade religiosa, tem-se que as entidades religiosas são imunes da incidência de impostos sobre patrimônio, renda e serviços, desde que sejam relacionadas com as suas finalidades;

c) Imunidades Não Autoaplicáveis: com previsão no art. 150, inciso VI, alínea “c”, tal norma alcança quatro pessoas jurídicas, sendo os Partidos Políticos (busca-se preservar a liberdade política), os Sindicatos de Empregados (proteção ao polo hipossuficiente na relação laboral), as Instituições de Educação (educação é dever do Estado, merecendo melhor proteção), e as Entidades de Assistência Social. Todavia para que tais pessoas gozem da imunidade devem requerêlas, caso contrário, serão tributadas normalmente; todavia tal imunidade trata somente da incidência de impostos sobre o patrimônio, a renda e os serviços, desde que relacionados com as finalidades essenciais das entidades, desde que sejam sem fins lucrativos e cumpram os requisitos legais.

d) Imunidade de Imprensa: confirmada pelo art. 150, inciso VI, alínea “d”, significa que são imunes a incidência de impostos sobre o papel destinada à impressão, bem como sobre as mídias escritas como livro, jornal e periódico. O dispositivo possui natureza objetiva, pois atingem bens ou coisas, no que tange, diretamente aos impostos - ICMS, IPI, II e IE e tão somente;

e) Imunidade Musical: com previsão no art. 150, inciso VI, alínea "e", possui como fundamento o combate à pirataria, o estímulo ao mercado fonográfico brasileiro e a ampliação da difusão de cultura da música a todas as classes sociais; de tal maneira, são objetos do presente dispositivo os fonogramas, os videofonogramas e os suportes matérias e arquivos digitais que o contenham, estando imunizados da incidência de impostos todas as fases de produção/ gravação de artistas brasileiros, bem como na comercialização em seus diversos suportes, tornando mais acessível seu consumo.

Logo, pode-se observar a importância das imunidades, tanto como garantia de certos valores, como políticos, religiosos, étnicos e outros, como também importante limitador do poder tributar.

\section{A Vedação de Efeitos Confiscatórios}

É da natureza constitucional que a carga tributária imposta ao contribuinte seja plausível, razão em que o constituinte quis, por bem, limitar o poder de tributar, particularmente no que tange o artigo 150, inciso IV da Constituição Federal de 1988: 
Art. 150. Sem prejuízo de outras garantias asseguradas ao contribuinte, é vedado à União, aos Estados, ao Distrito Federal e aos Municípios: (...)

IV - utilizar tributo com efeito de confisco;

Com tamanha intensidade, o legislador objetivou limitar o poder estatal, com a finalidade de que os tributos não possuíssem efeitos confiscatório, para Sabbag “o conceito de confisco tem sido apresentado como a absorção da propriedade particular pelo Estado, sem justa indenização" (SABBAG, 2016, p.243), analogamente Paulo Cesar Baria de Castilhoao reafirmar que:

\section{Confisco tributário consiste em uma ação do Estado, empreendida pela utilização do tributo, a qual retira a totalidade ou parcela considerável da propriedade do cidadão contribuinte, sem qualquer retribuição econômica ou financeira por tal ato (CASTILHO, 2002, p.39).}

Semelhantemente, Aliomar Baleeiro manifesta que "tributos confiscatórios são aqueles que absorvem todo o valor da propriedade, aniquilam a empresa ou impedem o exercício de uma atividade lícita e moral" (BALEEIRO, 1960, p.237). Não o bastante, Ricardo Alexandre relata que:

O efeito confiscatório seria o tributo com incidência exagerada de forma que, absorvendo parcela considerável do patrimônio ou da renda produzida pelo particular, gerasse neste e na sociedade em geral uma sensação de verdadeira punição (ALEXANDRE, 2015, p.146)

Além do mais, o tributo não pode ser utilizado como sanção por ato ilícito. Ainda assim, Mazza (2015, p.300) relata que o citado princípio consiste na limitação do poder tributário do Estado em estabelecer patamares tributários nímios ${ }^{7}$, impedindo o exercício de atividade econômica, corolário dos princípios da razoabilidade e proporcionalidade da seara tributária.

Ad argumentandum, Montesquieu, já pronunciava no século XVIII que:

Para estabelecer
corretamente esta receita,
devem-se considerar tanto
as necessidades do Estado
quanto as necessidades dos
cidadãos. Não se deve tirar
das necessidades reais do
povo para dar às
necessidades imaginárias
do Estado ... não há nada
que a sabedoria e a
prudência devam melhor
regrar do que esta porção
que se retira e esta porção
que se deixa para os
súditos.(MONTESQUIEU,
1996, p.221)

Sabbag (2016, p. 239 e 249) refere-se ao princípio da vedação do confisco como um "desafio" aos doutrinadores, pelo fato da legislação não "ofertar critérios objetivos para a sua verificação"; enfrentando a problemática definição objetiva dos "efeitos 
de confisco" expresso no texto constitucional, visto a impossibilidade de um método direto para a sua definição, ou ainda, "diante da miríade de problemas nos quais a temática pode se hospedar" em cada caso; o autor é claro ao declarar que "não há, no Brasil, parâmetros objetivos, com moldes cartesianos preestabelecidos, delimitadores do que vem a ser uma tributação tradutora de confiscatoriedade."

Analogamente, Harada (2015, p. 403/404) ressalta que ante a lacuna legal ou constitucional de uma regra consolidando o limite da tributação de cada contribuinte ou categoria de contribuintes, torna-se demasiadamente complexo estabelecer à carga tributária harmonizável à capacidade contributiva de cada um.

A definição dos efeitos confiscatórios é um tema de grande complexidade, tal que, muitos doutrinadores fogem do assunto. Todavia, há de se analisar que os efeitos confiscatórios podem ser vistos sobre duas óticas, seja pela carga tributária incidente em cada indivíduo, seja pela análise de cada tributo isoladamente. Ou seja, "se a soma dos diversos tributos incidentes representa carga que impeça o pagador de tributos de viver e se desenvolver, estar-se-á perante carga geral confiscatória" (BASTOS; MARTINS, 1990, p.162). Luiz Felipe Silveira Difini posiciona no mesmo sentido ao declarar que "a ocorrência de eventual efeito de confisco deve ser examinada em relação ao conjunto do sistema tributário”. (DIFINI, 2007, p.230)

Todavia, outros doutrinadores, não seguem o mesmo raciocínio, como Fábio Brun Goldschmidt GOLDSCHMIDT, 2004, p.283)declara que:

O limite da tributação deve ser o mesmo, quer se trate de uma única exigência fiscal, quer se trate de diversas exigências, pois o que se tem em conta são os efeitos, e não a (s) causa (s) de geração da destruição da propriedade ou liberdade do particular.

Por conseguinte, as buscas por um método de aplicação do referido princípio são incansáveis, encontrando-se vinculado ao contexto de cada caso concreto, realça RutiKazumiNakagaki ao dizer que "o princípio do não confisco pode assumir tanto a característica de limite objetivo quanto a de valor, de acordo com a sociedade em que tiver inserido" (NAKAGAKI, 2010, P.139), além de que, Carvalho (2002, p.54) e Goldschmidt (2004, p.89) asseguram que sua aplicação dependerá sempre da interpretação dos demais princípios e não isoladamente.

Além do mais, a limitação imposta pelo texto constitucional em seu artigo 150, IV, visa também, manter o equilíbrio da sociedade e economia, assim assegura Goldschmidt (2004, p.58) ao demonstrar por meio do economista americano Arthur Lafter, que nem sempre o incremento da tributação gera ampliação da arrecadação; a teoria do economista, também conhecida por "Curva de 
Lafter" mostra que após um marco aceitável, toda elevação da carga tributária passa a resultar em uma queda na arrecadação, ou seja, posterior a um ponto máximo maior a tributação, menor será a arrecadação; logo, este marco, auxilia em uma possível interpretaçãodos efeitos de confisco.

Por consequência, os efeitos confiscatórios podem ser vistos em alguns casos sobre tributos isolados, estando sua interpretação atada a outros princípios, em se tratando de Taxas, conforme descrição contida no artigo 145 , II da $\mathrm{CF} / 88$ :

Serão confiscatórias na medida em que o valor dos serviços públicos, e a remuneração relativa ao exercício regular do poder de polícia, venham a ser vultuosos, não guardando nenhuma

proporcionalidade com os custos, revelando-se incompatíveis com os fins perseguidos pelo interesse público (ausência de finalidade comercial). (MELO, 2003, p.34).

[...] com relação às taxas, só obliquamente pode se caracterizar o efeito do confisco. Se não houver a razoável correlação com o custo do serviço, o tributo será inválido por desnaturamento de sua base de cálculo. (DIFINI, 2007, p.207)

Outro meio confiscatório é a progressividade dos tributos, conforme entendimento do Supremo Tribunal Federal,

[...] - inexiste espaço de liberdade decisória para o Congresso Nacional, em tema de progressividade tributária, instituir alíquotas progressivas em situações não autorizadas pelo texto da Constituição [...] (SANTA CATARINA. Tribunal de Justiça. Repetição De Indébito - Contribuição De Seguridade Social - Ipês Servidores Civis E Militares Ativos - Previsão De Alíquota Progressiva Impossibilidade - Ausência De Previsão. Apelação Cível: AC 756537 SC 2009.075653-7. Apelante: IPREV - Instituto de Previdência do Estado de Santa Catarina

Apeladas: Florisbela da Silva e outros

Réu: Instituto de Previdência do Estado de Santa Catarina IPESC. Julgamento: $11 / 03 / 2010$.

Disponível em:http: $</ / \mathrm{tj}$ sc.jusbrasil.com.br/jurispru dencia/16036935/apelacao -civel-ac-756537-sc2009075653-7> acesso em: 19/06/2016).

Diante do exposto, tais exceções constitucionais respaldam-se na extrafiscalidade dos impostos; Roque Antônio Carrazza declara ser:

... o emprego dos meios tributários para fins não fiscais, mas ordinários (isto é, para disciplinar comportamentos de virtuais contribuintes, induzindo-os a fazer ou a deixar de fazer alguma coisa) (CARRAZA, 2006, p.374).

É o que acontece com o Imposto sobre a Propriedade Predial e Territorial Urbana 
(IPTU) ${ }^{8}$, a qual, permite a tributação progressiva com o fim de que o contribuinte cumpra a função social de sua propriedade, assim como também no Imposto sobre a Propriedade Territorial Rural (ITR) ${ }^{9} \mathrm{e}$ Imposto sobre Renda (IR) ${ }^{10}$.

Tal maneira exige uma análise diferenciada sobre os efeitos confiscatórios, pois como ensina Misabel Derzi, "alíquotas elevadas podem ser instituídas, mesmo superiores a $100 \%$ (cem por cento) em alguns casos, sem que se configure o confisco" (BALEEIRO, 2001, p.157). Pois, poderá ser feita visando o contribuinte de direito/direto e/ou contribuinte de fato/indireto (consumidor final); Goldschmidt (2004, p.245) e Difini (2007, p.176) entendem que deve se levar em consideração o contribuinte de direito, o qual poderá ter seu negócio destruído ou arruinado, por se tornar inviável a produção pelo fabricante, restando insuficiente a margem de lucro do produto.

Por outro lado, Jorge de Oliveira Vargas (2004, p.153) assevera que haverá o confisco, sob análise do contribuinte de fato quando a tributação sobre os bens de consumo não observarem o princípio da seletividade, o qual protege o médio vital.

Outro parâmetro a se explorar, é a tributação sobre a propriedade. Goldschmidt

\footnotetext{
${ }^{8}$ Artigo 156, inciso I da Constituição Federal de 1988.

9 Artigo 153, inciso VI da Constituição Federal de 1988.

10 Artigo 153, inciso III da Constituição Federal de 1988.
}

(2004, p.327) condizente com o pensamento de Aires Barreto, assegura que os efeitos confiscatórios estarão caracterizados quando restar ao contribuinte, devido à alta tributação, menor parcela da renda auferida pela sua propriedade, ou então, como leciona Regina Helena Costa com a "absorção total ou substancial da propriedade privada pelo Estado, sem a correspondente indenização". (COSTA, 2008, p.57).

Ainda na ânsia de encontrar uma aplicação objetiva do referido princípio constitucional, avaliza Eduardo Sabbag que "a entidade política que se atém aos limites da capacidade contributiva do cidadão mantémse na ideal zona intermediária entre o confisco e o mínimo razoável na tributação". (SABBAG, 2016, p.243). Sendo assim, afirma que os efeitos confiscatórios são caracterizados por dois aspectos. O primeiro aspecto ocorre quando a carga ultrapassar a barreira do mínimo existencial, a qual, nada mais é, que:

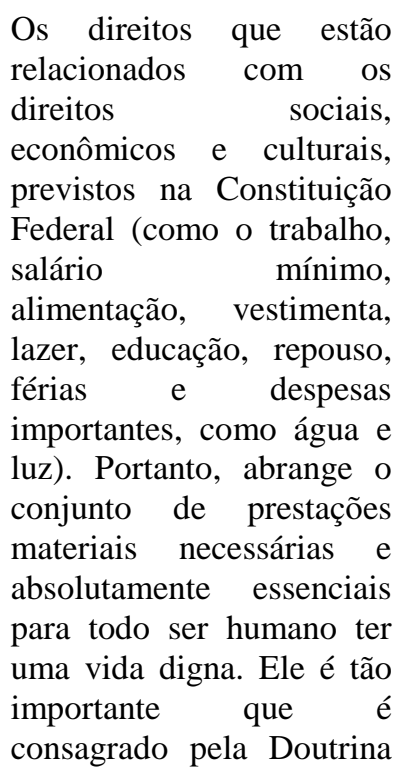


como sendo o núcleo do Princípio da Dignidade da Pessoa Humana, previsto no artigo $1^{\circ}$, III da $\mathrm{CF}$. (Suélen Coutinho do Nascimento - Disponível em

<http://antoniopires.jusbras il.com.br/artigos/12194066 0/minimo-existencial-xreserva-do-possivel> acesso em: 19/06/2016.

\section{O segundo aspecto configurador dos} efeitos confiscatórios ocorre quando transcender a capacidade contributiva do contribuinte mutilando integralmente ou mesmo que parcialmente a propriedade particular. O Supremo Tribunal Federal foi claro ao definir que:

A proibição constitucional do confisco em matéria tributária nada mais representa senão a interdição, pela Carta Política, de qualquer pretensão governamental que possa conduzir, no campo da fiscalidade, à injusta apropriação estatal, no todo ou em parte, do patrimônio ou dos rendimentos dos contribuintes,

comprometendo-lhes, pela insuportabilidade da carga tributária, o exercício do direito a uma existência digna, ou prática de atividade profissional lícita ou, ainda, a regular satisfação de suas necessidades vitais (educação, saúde, e habitação, por exemplo). A identificação do efeito confiscatório deve ser feita em função da totalidade da carga tributária, mediante verificação da capacidade de que dispõe o contribuinte - considerado o montante de sua riqueza

\author{
(renda e capital) - para \\ suportar e sofrer a \\ incidência de todos os \\ tributos que ele deverá \\ pagar, dentro de \\ determinado período. \\ ((ADIMC 2.010/DF, \\ Pleno, rel. Min. Celso de \\ Mello, j. 30-09-1999 - \\ disponível \\ em: \\ <http://stf.jusbrasil.com.br/ \\ jurisprudencia/738683/me \\ dida-cautelar-na-acao- \\ direta-de- \\ inconstitucionalidade-adi- \\ mc-2010-df> Acesso em: \\ $19 / 06 / 2016$
}

Mostrando claramente a importância de se verificar a totalidade da carga tributária e o limite do mínimo existencial a ser atingido, para que ao fim, possa julgar a existência ou não de efeitos confiscatórios.

Em outra decisão do STF apresenta-se:

\author{
RECURSO \\ EXTRAORDINÁRIO. \\ AGRAVO \\ REGIMENTAL. \\ CONTRIBUIÇÃO \\ PREVIDENCIÁRIA. \\ ALÍQUOTA
}

PROGRESSIVA. $1 . \mathrm{O}$ acórdão recorrido está em consonância com o entendimento do Plenário deste Supremo Tribunal que, no julgamento da ADI 2.010-MC, assentou que a instituição de alíquotas progressivas para a contribuição previdenciária dos servidores públicos ofende o princípio da vedação à utilização de qualquer tributo com efeito de confisco. Tal entendimento estende-se aos Estados e Municípios. 2. Agravo regimental improvido.

(STF - RE: 414915 PR, Relator: Min. ELLEN GRACIE, Data de 
Julgamento: 21/03/2006, Segunda Turma, Data de Publicação: DJ 20-042006. Disponível em: < http://stf.jusbrasil.com.br/j urisprudencia/14733442/ag regno-recursoextraordinario-re-414915pr>. Acesso em: $19 / 06 / 2016$

Demonstrando o mesmo posicionamento, se tornam confiscatórias as alíquotas progressivas para a contribuição previdenciária dos servidores públicos tornando-se exorbitantes ao aferir a carga tributária imposta a eles.

Ainda sobre a questão discutida, podese verificar outro posicionamento do STF:

\begin{abstract}
A taxa, enquanto contraprestação a uma atividade do Poder Público, não pode superar a relação de razoável equivalência que deve existir entre o custo real da atuação estatal referida ao contribuinte e o valor que o Estado pode exigir de cada contribuinte, considerados, para esse efeito, os elementos pertinentes às alíquotas e à base de cálculo fixadas em lei
\end{abstract}

- - Se o valor da taxa, no entanto, ultrapassar o custo do serviço prestado ou posto à disposição do contribuinte, dando causa, assim, a uma situação de onerosidade excessiva, que descaracterize essa relação de equivalência entre os fatores referidos (o custo real do serviço, de um lado, e o valor exigido do contribuinte, de outro), configurar-se-á, então, quanto a essa modalidade de tributo, hipótese de ofensa à cláusula vedatória inscrita no art. $150, \mathrm{IV}$, da Constituição da República. Jurisprudência. Doutrina. TRIBUTAÇÃO $\mathrm{E}$ OFENSA AO PRINCÍPIO DA PROPORCIONALIDADE - (Disponível em: <http://stf.jusbrasil.com.br/ jurisprudencia/771301/que stao-de-ordem-na-medidacautelar-na-acao-direta-deinconstitucionalidade-adimc-qo-2551-mg $>$ acesso em 19/06/2016)

Ratificando assim, o entendimento da confiscatoriedade das taxas, quando ultrapassam o custo do serviço prestado, tornando-o excessivas ao contribuinte, de tal modo que, infligem o princípio do não confisco.

\section{Considerações Finais}

Diante da presente análise, desvela-se que defronte ao poder de tributar do Estado, existe a necessidade de o legislador impor limites para que não ocorram atos arbitrários por parte dos representantes do Estado, salientando que o princípio da vedação dos efeitos confiscatórios dos tributos é um dos limites constitucionais impostos pelo legislador.

Entretanto, após explanação realizada constata que sua aplicação não é simples e demanda diversas considerações e interpretações, essencialmente o encadeamento aos outros princípios constitucionais-tributários. 
Sua análise dependerá de cada caso concreto, pois os efeitos tributários podem ser vislumbrados individualmente ou em conjunto, ou seja, pela carga tributária que envolver cada caso analisado.

Haverá casos em que sua aplicação será objetiva, por exemplo quando as taxas não fazem correlação ao custo do serviço, isto é, vão além destes, evidenciando a invasão patrimonial do contribuinte além do permitido; outra maneira também já entendida como confiscatória é a progressividade dos tributos, salvo os casos previstos em lei.

Por outro lado, ratificando a complexidade de eventual princípio, existem tributos que apesar de possuírem alíquotas superiores a $100 \%$ (cem por cento), no caso de alguns produtos e serviços, como o cigarro, não são considerados confiscatórios. Tal fato, embora aparentemente possa parecer confiscatório, a referida alíquota não inviabiliza o negócio a ponto de forçar a desaceleração da produção e do consumo e/ou a impossibilitar que haja margens de lucros suficientes. Neste caso, a aplicação do princípio de vedação dos efeitos confiscatórios está diretamente ligada ao princípio da seletividade.

Por outro lado, o tributo também agirá de forma confiscatória quando atinge maior parcela da propriedade ou renda do contribuinte sem que tenha devida indenização ou retorno estatal, ou então, quando abarque porção do mínimo existencial do indivíduo.

Portanto, os doutrinadores e jurisprudências sintetizam ao afirmar que os efeitos confiscatórios se fazem presentes quando o Estado, ao utilizar do poder de tributar, o exercem com abusividade sobre o contribuinte, extrapolando os limites de forma a aniquilar parcialmente ou integralmente a propriedade ou renda do indivíduo, restandose inviável a continuidade de suas atividades ou sobrevivência.

Ademais, verifica-se que a limitação imposta pelo legislador atua não só em defesa do contribuinte, mas do próprio Estado, uma vez que, diante de efeitos confiscatórios torna-se indesejável a permanência do cidadão na atividade o forçando a abandonar, deixar suas atividades, ou ainda, tornar se inadimplente, o que resulta na diminuição da arrecadação estatal, meio de subsistência do Estado.

Por fim, pela importância do princípio da vedação dos efeitos confiscatórios aliado ao princípio constitucional da segurança jurídica, o princípio ora analisado precisava ser tratado pela doutrina e jurisprudência pátria com maior objetividade, facilitando sua aplicação e resguardando, ainda mais, o sujeito passivo da relação jurídico-tributária. 


\section{Referências}

ALEXANDRE, Ricardo. Direito Tributário Esquematizado, $9^{a}$ edição. São Paulo: Método, 2015.

AMARO, Luciano, Direito Tributário

Brasileiro, 14.ed. São Paulo: Saraiva, 2008.

BALEEIRO, Aliomar. Limitações

Constitucionais ao Poder de Tributar. Rio de Janeiro: Forense, 1960.

BRASIL. Código Tributário Nacional - Lei $\mathrm{n}^{\circ}$ 5.172, de 25 de outubro de 1966. Disponível em:

http://www.planalto.gov.br/ccivil_03/leis/L51 72Compilado.htm acesso em 19/06/2016.

BRASIL. Constituição (1988). Constituição da República Federativa do Brasil, 1988. Disponível em: < http://www.planalto.gov.br/ccivil_03/constitui cao/constituicaocompilado.htm> acesso em: 19/06/2016.

CARraZA, Roque Antônio. Curso de Direito Constitucional Tributário, $24^{\mathrm{a}}$ edição. São Paulo: Malhereios Editores, 2008.

CASTILHO, Paulo Cesar Baria de. Confisco Tributário. São Paulo: RT, 2002;

COSTA, Regina Helena. Limitações ao Poder de Tributar na Constituição Brasileira. São Paulo: Malheiros, 2008.

DERZI, Misabel. Debate no V Congresso Brasileiro de Direito Tributário. RDTributário, São Paulo: RT, 1991 ------ apud. In: BALEEIRO, Aliomar. Limitações constitucionais ao Poder de Tributar. 7.ed. atual. por Misabel Abreu Machado Derzi. Rio de Janeiro: Forense, 2001.

DIFINI, Luiz Felipe Silveira. Proibição de Tributos com Efeito de Confisco. Porto Alegre: Livraria do Advogado, 2007.

FERREIRA, Aurélio Buarque de Holanda, Mini Aurélio Século XXI Escolar: O minidicionário da língua portuguesa, 4.ed.rev.ampliada - Rio de Janeiro: Nova Fronteira, 2001.

GOLDSCHMIDT, Fábio Brun. O princípio do não-confisco no direito tributário. São Paulo: RT, 2004.

MACHADO, Hugo de Brito. Curso de Direito Tributário. São Paulo: Malheiros Editores, 2008.

MACHADO. Hugo de Brito. Curso de Direito Tributário. $29^{\mathrm{a}}$ Ed. São Paulo: Malheiros, 2008.

MAZZA, Alexandre. Manual de Direito

Tributário. São Paulo: Saraiva, 2015.

MONTESQUIEU, Charles de Secondat, Baron de, 1689-1755. O Espírito das leis; apresentação Renato Janine Ribeiro; Tradução Cristina Murachco. - São Paulo: Martins Fontes, 1996.

NASCIMENTO, Suélen Coutinho do Nascimento. Mínimo existencial x reserva do possível.Jusbrasil. Disponível em: < http://antoniopires.jusbrasil.com.br/artigos/12 1940660/minimo-existencial-x-reserva-dopossivel> acesso em 19/06/2016.

\section{SABBAG, Eduardo. Manual de Direito}

Tributário. 6. ed. - São Paulo: Saraiva, 2014. Manual de Direito Tributário.

5 Edição - São Paulo: Saraiva, 2013.

\section{Manual de Direito Tributário.}

8a Ed. - São Paulo: Saraiva, 2016

SANTA CATARINA. Tribunal de Justiça. Repetição De Indébito - Contribuição De Seguridade Social - Ipês - Servidores Civis E Militares Ativos - Previsão De Alíquota Progressiva - Impossibilidade - Ausência De Previsão. Apelação Cível: AC 756537 SC 2009.075653-7. Apelante: IPREV - Instituto de Previdência do Estado de Santa Catarina Apeladas: Florisbela da Silva e outros - Réu: Instituto de Previdência do Estado de Santa Catarina IPESC. Julgamento:11/03/2010. 
Disponível em: http: <//tj-

sc.jusbrasil.com.br/jurisprudencia/16036935/a

pelacao-civel-ac-756537-sc-2009075653-7>

acesso em: 19/06/2016).

SCHOUERI, Luís Eduardo. Direito

Tributário. $4^{\text {a }}$ Ed. - São Paulo: Saraiva, 2014.

STF - ADI-MC: 2010 DF, Relator: CELSO

DE MELLO, Data de Julgamento:

30/09/1999, Tribunal Pleno, Data de

Publicação: DJ 12-04-2002 disponível em:

$<$ http://stf.jusbrasil.com.br/jurisprudencia/738

683/medida-cautelar-na-acao-direta-de-

inconstitucionalidade-adi-mc-2010-df >

Acesso em: 19/06/2016

STF - ADI-MC-QO: $2551 \mathrm{MG}$, Relator:

CELSO DE MELLO, Data de Julgamento:

02/04/2003, Tribunal Pleno, Data de

Publicação: DJ 20-04-2006. Disponível em:

<http://stf.jusbrasil.com.br/jurisprudencia/771

301/questao-de-ordem-na-medida-cautelar-

na-acao-direta-de-inconstitucionalidade-adi-

mc-qo-2551-mg> acesso em 19/06/2016.

STF - RE: 414915 PR, Relator: Min. ELLEN

GRACIE, Data de Julgamento: 21/03/2006,

Segunda Turma, Data de Publicação: DJ 20-

04-2006. Disponível em:

<http://stf.jusbrasil.com.br/jurisprudencia/147

33442/agregno-recurso-extraordinario-re-

414915-pr> Acesso em:19/06/1016.

VARGAS, Jorge de Oliveira. Princípio do não-confisco como garantia constitucional da tributação justa. Curitiba: Juruá, 2004. 